\title{
NUMERICAL ANALYSIS OF THE CHILD LUMBAR SPINE MOVEMENTS IN THE MOTOR VEHICLE CRASH
}

Igor Saveljić ${ }^{1}$, Slavica Mačužić ${ }^{2}$, Nenad Filipović ${ }^{3}$

UDC: UDC:629.11.02/098

\section{INTRODUCTION}

A seat belt, as is known, has a role to protect vehicle passengers in case of a sudden stop or traffic accident. Restraint systems such as seat belts and airbags have a great role in decreasing the number of children who die in traffic accidents [1]. Child restraint systems are often used incorrectly. An estimated $46 \%$ of car and booster seats are misused in a way that could reduce their effectiveness [2]. The most common injuries that occur in children are cervical spine fractures and lumbar spinal dislocations (Figure 1).

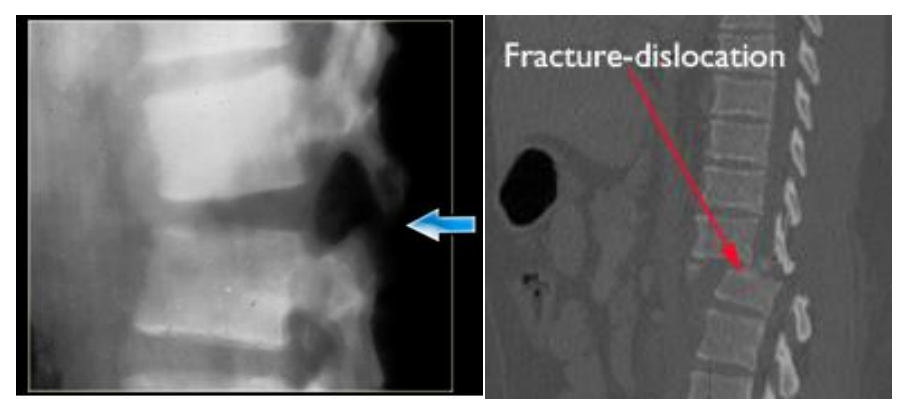

Figure 1 Spinal injuries

Cases of serious cervical and lumbar spinal cord injury have been described for many years [3]. These injuries occur when a child uses the wrong shoulder belt, or when the shoulder belt is not present (Figure 2) [4], [5].

\footnotetext{
${ }^{1}$ Igor Saveljić, Ph. D. student, University of Kragujevac, Faculty of Engineering, 6 Sestre Janjić Str., 34000 Kragujevac, Serbia, isaveljic@kg.ac.rs

${ }^{2}$ Slavica Mačužić, Ph. D. student, University of Kragujevac, Faculty of Engineering, 6 Sestre Janjić Str., 34000 Kragujevac, Serbia, slavicamacuzic89@gmail.com

${ }^{3}$ Nenad Filipović, Ph. D., prof., University of Kragujevac, Faculty of Engineering, 6 Sestre Janjić Str., 34000 Kragujevac, Serbia, fica@kg.ac.rs
} 

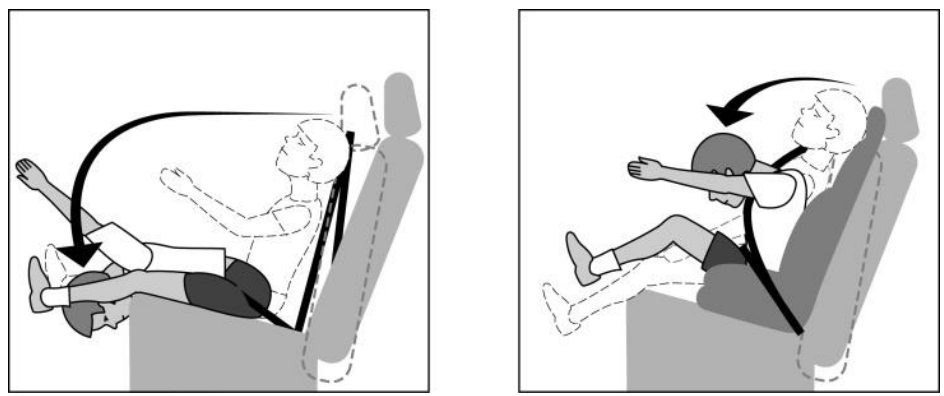

Figure 2 Incorrect and correct the seat belt use

The aim of this study was to analyse the behaviour of the lower spine during emergency braking in two cases, using the finite element. 3D model of a L4-L5 vertebra has been tested in bending to determine the displacements and von Misses stresses. In this way, the numerical simulations can determine the degree of injury to children in a car accident.

\section{MATERIALS AND METHODS}

A 3D computer model of a L4-L5 vertebra was developed using the CT scans. The CT scans were read into Mimics visualization software, where the images were segmented by thresholding to obtain vertebra model, with intervertebral disc (Figure 3).

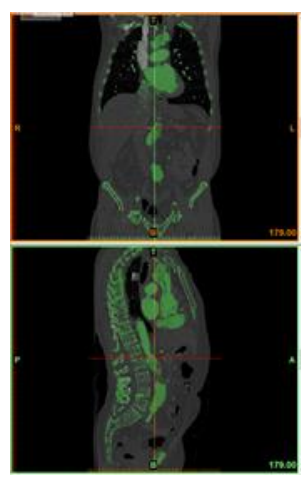

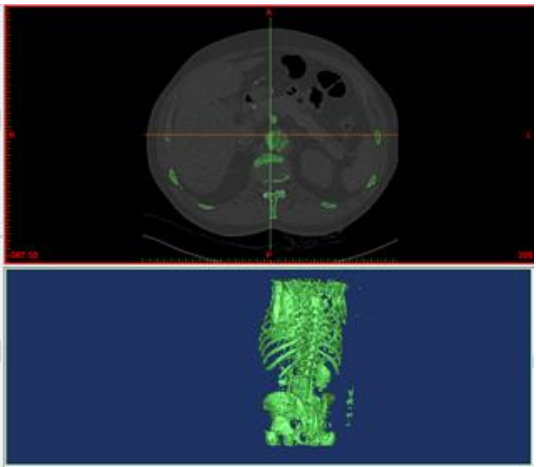

a)

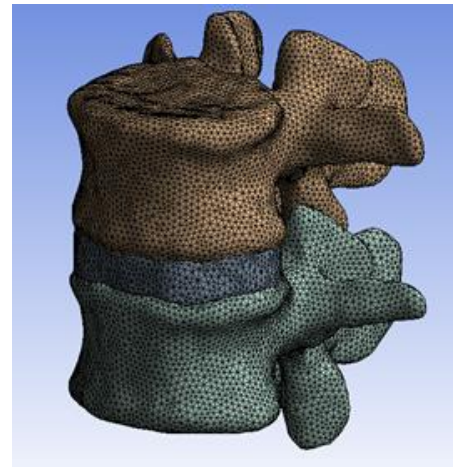

b)

Figure 3 The process for the 3D FE model: a) CT scan and $3 D$ reconstruction of the $C T$ scans, and $b$ ) meshing of the $3 D$ FE model

After creating a 3D model, we used Ansys R14.5 to generate 3D mesh (Figure 2b). Linear tetrahedron was used as the final element. Finite element mesh consists of three groups of elements: finite elements that represent cortical bone, finite elements that represent nucleus and finite elements that represent annulus. Mechanical properties assigned to the each material are summarized in Table 1 [6], [7]. 
Table 1 Material properties of components of the spine

\begin{tabular}{|c|c|c|}
\hline Name of component & Young's Modulus [MPa] & Poisson's ratio \\
\hline Cortical bone & 12000 & 0.3 \\
\hline Nucleus & 1 & 0.49 \\
\hline Annulus & 4.2 & 0.45 \\
\hline
\end{tabular}

The boundary condition was defined by fixed nodes at the bottom of the model, while on the upper surface of the model set the certain value of the force. Using Hyper Physics [8], we got the value of the force, that acting on the body in car crash $(4000 \mathrm{~N}$, calculated for children from $30 \mathrm{~kg}$ weight and speed of the car $70 \mathrm{~km} / \mathrm{h}$ ). In the case when the belt is used properly, it has limited the movement the model to $100 \mathrm{~mm}$.

One of the basic principles of continuum mechanics is the principle of virtual work. Starting from the equilibrium equations [9] by applying the boundary conditions can be equal to the virtual work of internal and external forces:

$$
\delta W_{\text {int }}=\delta W_{\text {ext }}
$$

Virtual work of the previous equation in matrix form can be written as:

$$
\delta W_{\mathrm{int}}=\int_{V} \delta \mathbf{e}^{T} \boldsymbol{\sigma} d V \quad \delta W_{e x t}=\int_{V} \delta \mathbf{u}^{T} \mathbf{F}^{V} d V+\int_{S^{\sigma}} \delta \mathbf{u}^{T} \mathbf{F}^{S} d V+\sum_{i} \delta \mathbf{u}^{T} \mathbf{F}^{(i)}
$$

Applying the principle of virtual work and the constitutive relations for linear elastic material in matrix form

$$
\boldsymbol{\sigma}=\mathbf{C e}
$$

and by applying the concept isoparametric interpolation [10] in the finite element, we can write the equation of equilibrium finite elements

$$
\mathbf{K U}=\mathbf{F}_{\text {ext }}
$$

where $\mathrm{K}$ is element stiffness matrix, $\mathrm{C}$ - elastic constitutive matrix, e = BU - matrix deformation, $\mathrm{U}$ - displacements at the nodes, $\mathrm{F}_{\text {ext }}$ - external forces in the element nodes.

In the linear analysis of solids a basic assumption is that the moving solids is infinitesimally small and that the material is linearly elastic. Also, the assumption is that the nature of the boundary conditions remain unchanged under the action of external loads. Under these assumptions, the equations of equilibrium is derived for finite element structural analysis. 


\section{RESULTS}

In this this section, we present the results of numerical simulation. We investigated two cases. Figure 4 show results of the first numerical analysis - simulation of a correct seat belt use.

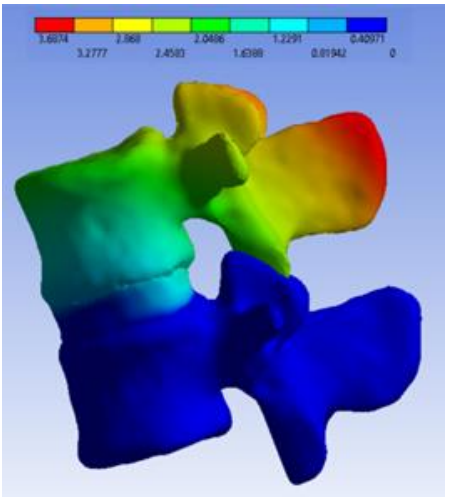

a)

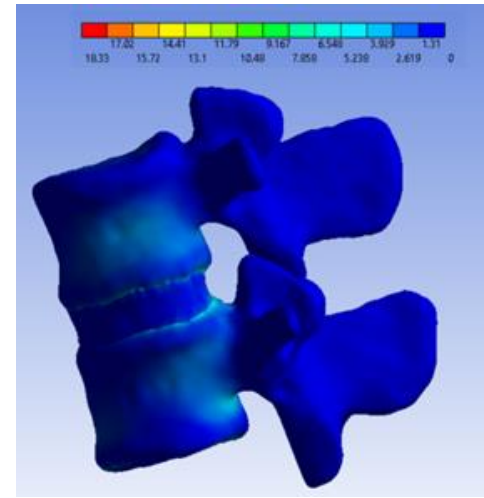

b)

Figure 4 Numerical results of case 1: a) displacement [mm],

b) Von Mises stress distirbution [Pa]

As can be seen, the greatest value of displacement of the upper vertebra part is 3.68 $\mathrm{mm}$. In the area near the spinal cord recorded the movement of the annulus of $1.35 \mathrm{~mm}$. Figure $4 \mathrm{~b}$ present Von Mises stress distribution along studied model. The highest recorded value of this stress is $18.73 \mathrm{MPa}$, in the area of contact vertebra body and intervertebral disc. These zones leads to cervical spine fractures, so it is of great relevance correct use of the seat belt. Figure 5 shows stress distribution for second case.

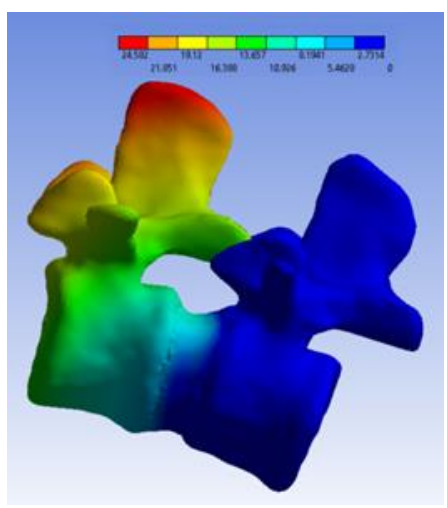

a)

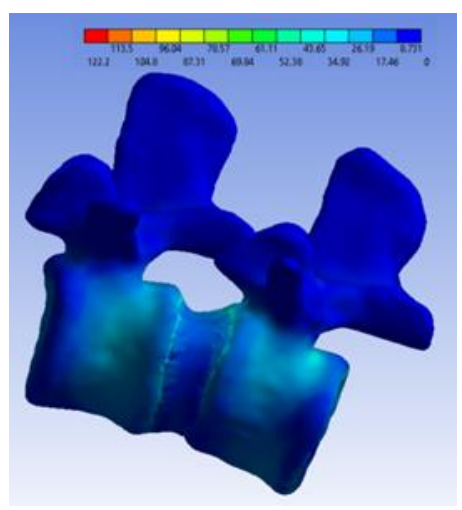

b)

Figure 5 Numerical results of case 2: a) displacement [mm], b) Von Mises stress distirbution [Pa] 
Improper use seat belts, in the event of an car accident, leading to large displacement of parts of the spine. As can be seen from Figure 5, the greatest displacement go to enormous $24.52 \mathrm{~mm}$. Moving the intervertebral disc go to $13.6 \mathrm{~mm}$. The von Misses stress reaches a value of $122.2 \mathrm{MPa}$. All this leads to serious damage to the spine and improper functioning of its parts.

\section{CONCLUSIONS}

The FEA performed in this study demonstrated pattern of von Misses stress distribution and displacement through the lumbar spine (segment L4-L5) during car accident. We studied the correct and incorrect way binding belt child in the back seat. Results of this study showed that the displacement of L4 vertebra body in the first case is $3.68 \mathrm{~mm}$, which is a good result and secure value for the spine. The highest von Misses stress has a value $18.73 \mathrm{MPa}$. Improper use seat belts, in the event of an car accident leading to large displacement of the L4 vertebra body. Greatest value in this case has $24.52 \mathrm{~mm}$. Intervertebral disc has a large displacement, even $13.6 \mathrm{~mm}$, which leads to cervical spine fractures. These results give a clearer picture of the severity of injuries of the spine during sudden braking of the car. It is necessary that everyone understand the seriousness of the problem.

\section{ACKNOWLEDGMENTS}

This research supported by the Ministry of Education, Science and Technological Development of Republic of Serbia through Grant TR35041.

\section{REFERENCES}

[1] http://www.cdc.gov/motorvehiclesafety/child_passenger_safety/cps-factsheet.html, Accessed 19.07.2016.

[2] Greenwall, N.K.: "National Highway Traffic Safety Administration", 2015, Washington, D.C.

[3] Agran, P., Dunkle, D., Winn, D.: "Injuries to a sample of seat belted children evaluated and treated in a hospital emergency room", J Trauma Vol. 27, 2007, pp. 5864.

[4] Arbogast, K.B., Durbin, D.R., Kallan, M.J.: "The role of restraint and seat position in pediatric facial fractures", J Trauma, Vol. 52, 2002, pp. 693-698.

[5] Winston, F.K., Durbin, D.R., Kallan, M.J.: "The danger of premature graduation to seat belts for young children", Pediatrics, Vol. 105, 2000, pp. 1179-1183.

[6] Park, W.M., Park, Y.S., Kim, K., Kim, Y.H.: "Biomechanical comparison of instrumentation techniques in treatment of thoracolumbar burst fractures: A finite element analysis", J Orthop Sci, Vol. 14, 2009, pp. 443-449.

[7] Wang, H., Wang, X., Chen, W., Zhao, F., Xiang, L., Zhou, Y., Cheng, C.: "Biomechanical comparison of interspinous distraction device and facet screw fixation system on the motion of lumbar spine: a finite element analysis", Chin Med J (Engl), Vol. 127, 2014, pp. 2078-2084.

[8] http://hyperphysics.phy-astr.gsu.edu/hbase/carcr2.html, Accessed 19.07.2016.

[9] Kojic, M., Filipovic, N., Stojanovic, B., Kojic, N.: "Computer Modeling in Bioengineering - Theoretical Background, Examples and Software", John Wiley and Sons, 2008, Chichester, England.

[10] Bathe, K.J., "Finite Element Procedures", Prentice-Hall, Inc., 1996, Englewood Cliffs, N.J. 
Intentionally blank 